\title{
Short-Term Mechanical Ventilation Increases Airway Reactivity in Rat Pups
}

\author{
SABINE C. IBEN, MUSA A. HAXHIU, CAROL F. FARVER, MARTHA J. MILLER, AND RICHARD J. MARTIN \\ Department of Pediatrics [S.C.I., M.A.H., M.J.M., R.J.M.], Rainbow Babies and Children's Hospital, Cleveland, Ohio, 44106; Department \\ of Anatomic Pathology [C.F.F.], Cleveland Clinic Foundation, Cleveland, Ohio, 44195
}

\begin{abstract}
We used a rat pup model to delineate whether mechanical ventilation of $\leq 4 \mathrm{~h}$ duration in the absence of supplemental oxygen contributes to the development of airway hyperreactivity. Eight-day-old rat pups were assigned to unventilated normoxic controls, ventilated under normoxic conditions, ventilated under hyperoxic conditions $\left(100 \% \mathrm{O}_{2}\right)$, or unventilated hyperoxic groups $\left(>95 \% \mathrm{O}_{2}\right)$. After each intervention, they were returned to their mothers. On d 10 of life, all animals were anesthetized, paralyzed, and ventilated to measure pulmonary function. Total lung resistance $\left(\mathrm{R}_{\mathrm{L}}\right)$ and dynamic lung compliance (Cdyn) were measured in response to increasing intravenous doses of methacholine (0.03$1 \mu \mathrm{g} / \mathrm{g}$ ) by head-out body plethysmography. Injection of methacholine caused a dose-dependent increase in $\mathrm{R}_{\mathrm{L}}$ and decrease in Cdyn. The response of both $\mathrm{R}_{\mathrm{L}}$ and Cdyn to methacholine was significantly potentiated by prior exposure to mechanical ventilation when compared with unventilated normoxic controls. The addition of hyperoxia to mechanical ventilation did not further potentiate responses to methacholine. Mechanical ventilation did not alter lung myosin or the number of inflammatory cells in airways of room air ventilated versus unventilated control animals. We conclude that a brief period of mechanical ventilation in rat pups increases airway reactivity $48 \mathrm{~h}$ after such exposure in the presence as well as absence of hyperoxic exposure. This represents a potentially important model to investigate the mechanisms involved in airway hyperreactivity induced by neonatal lung injury. (Pediatr Res 60: 136-140, 2006)
\end{abstract}

$\mathrm{P}$ remature infants with a history of mechanical ventilation and/or BPD have a high incidence of reactive airway disease in later childhood and adolescence $(1,2)$. A combination of ventilator-induced lung injury and oxygen toxicity during a critical period of lung development has been implicated in the pathogenesis of chronic lung disease in this population (3). However, using data from clinical studies in infants, it is difficult to separate the relative contributions of mechanical ventilation versus high inspired oxygen. Furthermore, it is not clear to what extent ventilator-induced functional or structural changes in the developing airway contribute to airway hyperreactivity in former preterm infants.

The changes in airway reactivity induced by prolonged exposure of rat pups to hyperoxia have been well described by ourselves and others (4-7). Unfortunately, using an animal

Received September 21, 2005; accepted March 17, 2006.

Correspondence: Sabine Iben, M.D., Division of Neonatology, Rainbow Babies and Children's Hospital, 11100 Euclid Ave., Cleveland, OH 44106; e-mail: Sabine.iben@case.edu

Funded by National Institutes of Health grant number HL 56470.

DOI: 10.1203/01.pdr.0000227447.55247.7d model of hyperoxic exposure alone without additional mechanical ventilation does not seem to be consistent with clinical practice in neonatology.

There is very limited information on the potential changes in airway reactivity caused by ventilator-induced lung injury in early life. Fukunaga et al. (8) have shown that intermittent mechanical ventilation over a period of $7 \mathrm{~d}$ induced increased tracheal contractile responses measured under in vitro conditions in 7-wk-old rats. To our knowledge, the effect of mechanical ventilation on airway reactivity has not been studied in the newborn rat model under in vivo conditions. Therefore, the purpose of this study was to develop an immature animal model that would allow us to delineate the role of short-term mechanical ventilation on airway function in the absence and presence of concurrent oxygen exposure. The rat pup model was chosen since, similarly to the human, alveolarization is not completed at time of birth in this species (9). We hypothesized that short-term mechanical ventilation followed by recovery in rat pups would predispose to subsequent airway hyperreactivity and that the presence of hyperoxia would aggravate the process.

\section{METHODS}

Animal model. Newborn Sprague-Dawley rat pups from multiple litters (Zivic-Miller Laboratories, Zelienople, PA) were assigned to either one of three intervention groups, or one control group on d 8 of life. The control group consisted of 13 animals that remained with their mothers and received no intervention. The three experimental groups comprised the following: normoxic ventilation, hyperoxic ventilation, and hyperoxic exposure in the absence of ventilation.

Seven animals comprised the normoxic ventilated group. On d 8 of life, they were anesthetized with repeated intraperitoneal doses of ketamine/ xylazine $(0.25 \mathrm{mg} / 0.05 \mathrm{mg})$, intubated with 22-gauge Teflon tubing, and ventilated with a Harvard rodent ventilator (model 683, adjusted for small tidal volumes; Harvard Apparatus, Holliston, MA) for $4 \mathrm{~h}$ or until the effect of anesthesia subsided (mean, $2.7 \mathrm{~h}$; range, $1.7-4 \mathrm{~h}$ ). Ventilatory support was given with a rate of 100 breaths $/ \mathrm{min}$ and a tidal volume $10 \mathrm{~mL} / \mathrm{kg}$ in $21 \%$ oxygen. Peak inspiratory pressures did not exceed $16 \mathrm{~cm} \mathrm{H}_{2} \mathrm{O}$. Arterial blood gases sampled in another four animals demonstrated moderate hypocapnia, with an mean $\mathrm{PCO}_{2} 23 \pm 7 \mathrm{~mm} \mathrm{Hg}, \mathrm{PaO}_{2} 47 \pm 18 \mathrm{~mm} \mathrm{Hg}$, and pH $7.51 \pm 0.07$ without evidence of significant metabolic acidosis (mean $\mathrm{HCO}_{3} 18 \pm 5$ ). As spontaneous ventilatory efforts increased, the animals were weaned from

Abbreviations: BPD, bronchopulmonary dysplasia; Cdyn, dynamic compliance; $\mathbf{R}_{\mathbf{L}}$, lung resistance 
ventilation by decreasing the ventilator rate. When the animals were fully responsive they were returned to their mothers.

A subsequent series of experiments was designed to determine whether hyperoxic exposure superimposed on mechanical ventilation would have an additive effect on airway function. Eight animals were ventilated for $4 \mathrm{~h}$ in $100 \%$ oxygen on identical ventilator settings and protocol on d 8 of life. In this set of experiments, the anesthetic dose of ketamine/xylazine was increased to $0.5 \mathrm{mg} / 0.1 \mathrm{mg}$ i.p. so all animals could be maintained for a full $4 \mathrm{~h}$ on mechanical ventilation.

Thirteen littermates comprising the hyperoxic exposure group were exposed to $>95 \%$ oxygen only over a 4 -h period on $\mathrm{d} 8$ of life. The hyperoxic environment was achieved by continuous oxygen delivery $(2 \mathrm{~L} / \mathrm{min})$ to a sealed Plexiglas chamber. Oxygen concentration was monitored continuously with an oxygen analyzer (TED 60T; VWR, West Chester, PA). This group was designed to serve as additional controls for the hyperoxic ventilated animals.

We also sought to determine a potential confounding effect of the presence of an endotracheal tube on subsequent airway reactivity. Therefore, an additional group of eight rat pups was anesthetized and intubated for a period of $1 \mathrm{~h}$ on $\mathrm{d} 8$ of life as described below without exposure to mechanical ventilation. Again, they were returned to their mothers and maintained on room air. On d 10 of life, they were compared with littermates $(n=8)$ as outlined by the experimental protocol below.

Experimental protocol. At $10 \mathrm{~d}$ of age ( $2 \mathrm{~d}$ after intervention), pulmonary mechanics were measured on all rat pups as follows. The rat pups were anesthetized with urethane i.p. $0.2 \mathrm{mg} / \mathrm{kg}(8 \mathrm{~g} / 18 \mathrm{~mL})$, tracheotomized just below the larynx, and intubated with a tracheal cannula consisting of PE-160 tubing (1.57 mm OD). The tracheal cannula was connected to a Harvard rodent ventilator (model 683, adjusted for small tidal volumes), and by a side port to a pressure transducer. The animals were ventilated with $30 \%$ inspired $\mathrm{O}_{2}$, a tidal volume of $8 \mathrm{~mL} / \mathrm{kg}$, and a rate of 100 breaths $/ \mathrm{min}$. Next, a venous catheter (silastic laboratory tubing, ID $0.51 \mathrm{~mm}$, OD $0.94 \mathrm{~mm}$ ) was inserted in the external jugular vein for venous access. A venous blood gas was obtained in select animals and ventilator settings adjusted for a target $\mathrm{PCO}_{2}$ $35-45 \mathrm{~mm} \mathrm{Hg}$. The rats were placed in a head- out body plethysmograph made from a $120-\mathrm{mL}$ syringe. The animal was paralyzed with repeated doses of gallamine $\left(20 \mathrm{mg} / \mathrm{kg}\right.$ ) to suppress respiratory efforts. Baseline $\mathrm{R}_{\mathrm{L}}$ and Cdyn were recorded using Buxco software (Buxco, Wilmington, NC) (10). Bronchoconstriction was induced by increasing concentrations $(0.03-1 \mu \mathrm{g} / \mathrm{g})$ of the cholinergic agonist methacholine, given intravenously every $3 \mathrm{~min}$. The five respiratory cycles at peak response were analyzed and averaged.

At the end of the experiment a blood gas was obtained to assure the well being of each animal. Data from all animals with a venous $\mathrm{pH}$ of $\geq 7.25$ and base deficit $\leq-10$ were included in the analysis. Approximately $50 \%$ of all animals had to be excluded due to blood gas anomalies or instrumentation difficulties.

The study was approved by the Institutional Animal Care and Use Committee of case western reserve University.

Lung histology. Tissue was obtained from an additional five control and five normoxic ventilated rat pups. Ventilated animals were killed $2 \mathrm{~d}$ after a 4-h period of normoxic ventilation. They were euthanized with an overdose of anesthetic, and their lungs were inflated with $10 \%$ formalin at a pressure of 20 $\mathrm{cm} \mathrm{H}_{2} \mathrm{O}$ for $15 \mathrm{~min}$ and removed. Fixed lungs were cut into 5-mm sagittal sections, embedded in paraffin, cut into $5-\mu \mathrm{m}$ tissue sections, and placed on charged microscopic slides. Sections were stained with hematoxylin and eosin. A pathologist (CF) blinded to the treatment group analyzed the sections for qualitative histologic changes. All peripheral airways $(100-400 \mu \mathrm{m}$ in diameter) were evaluated for amount of inflammation by counting the number of inflammatory cells (neutrophils or lymphocytes)/100 epithelial cells. Airway smooth muscle was evaluated using a histochemical stain for connective tissue (Movat) on all sections.

Distal trachea samples from a different group of five normoxic ventilated and five control animals were assessed for signs of tracheal trauma.

Western blotting for myosin content. Lung tissue was obtained from another series of 10 control and 10 normoxic ventilated rat pups that were killed at $10 \mathrm{~d}$ of age, $2 \mathrm{~d}$ after a 4 -h period of normoxic ventilation. They were euthanized, and their lungs dissected, frozen, and stored at $-80^{\circ} \mathrm{C}$. Lungs of control and experimental animals were processed for myosin content using Western blot, as previously described (5).

Statistical analysis. Baseline $\mathrm{R}_{\mathrm{L}}$ and Cdyn between groups were compared using one-way ANOVA with Newman-Keuls for post hoc analysis.

The effect of methacholine and comparisons between the pairs of animal cohorts used two-way ANOVA with repeated measures using change over baseline. In addition, specific methacholine doses were compared using post hoc analysis with unpaired $t$ test following two-way ANOVA with repeated measures. The number of inflammatory cells in peripheral airways/100 epi- thelial cells and the myosin content of ventilated and unventilated lungs were compared by unpaired $t$ test, and $p$ values $<0.05$ were considered significant.

\section{RESULTS}

Baseline characteristics. Comparison of baseline lung mechanics occurred $2 \mathrm{~d}$ after each intervention, as indicated in "Methods." Although there was an overall difference between values of baseline $\mathrm{R}_{\mathrm{L}}$ and Cdyn between groups (one-way ANOVA, $p<0.001$ and $p<0.05$, respectively), there were no significant differences for baseline values between relevant group comparisons. These data are presented in Table 1.

Effect of exposure to mechanical ventilation on lung mechanics. We evaluated the effect of up to $4 \mathrm{~h}$ of mechanical ventilation under normoxic conditions on lung mechanics recorded $2 \mathrm{~d}$ after the intervention. Initial comparison was made with unventilated normoxic controls.

Intravenous administration of methacholine produced a dose-dependent increase in $\mathrm{R}_{\mathrm{L}}$ in all studied animals $(p<$ $0.0001)$. Ventilated animals compared with unventilated controls exhibited a significantly greater change in $\mathrm{R}_{\mathrm{L}}$ over baseline in response to increasing doses of intravenous methacholine from 0.03 to $1 \mu \mathrm{g} / \mathrm{g}$ ( $p=0.0048$; Fig. $1 A)$. Specifically, there were significantly increased responses of ventilated animals at doses of 0.6 and $1 \mu \mathrm{g} / \mathrm{g}(p<0.05)$. Furthermore, intravenous methacholine decreased Cdyn in a dosedependent fashion, with significantly greater decline in Cdyn in experimental animals compared with controls $(p<0.01$; Fig. $1 B)$

Effect of mechanical ventilation and superimposed hyperoxia on airway reactivity. To investigate the role of hyperoxic exposure on airway reactivity during mechanical ventilation, an additional group of animals $(n=8)$ was ventilated with $100 \% \mathrm{O}_{2}$ for $4 \mathrm{~h}$. Rat pups ventilated under normoxic conditions served as controls for this analysis. Airway responses of ventilated animals to methacholine were not altered by the addition of hyperoxia ( $p=0.98$; Fig. $2 A)$, and changes in Cdyn did not differ between groups ( $p=0.74$; Fig. $2 B$ ).

Effect of hyperoxic exposure on airway reactivity. Finally, we sought to determine whether exposure to $4 \mathrm{~h}$ of hyperoxia alone affected airway responses in nonventilated, unintubated rat pups $(n=13)$. When comparison was made to unventilated, unintubated normoxic controls, responses of $\mathrm{R}_{\mathrm{L}}(p=$ 0.82 ) were comparable. However, there was a significant greater decrease in Cdyn in response to methacholine in hyperoxia-exposed animals ( $p<0.01$; Fig. 3). Rats ventilated under hyperoxic conditions had significantly greater airway responses to methacholine compared with rats exposed to

Table 1. Baseline lung mechanics specified by subgroups

\begin{tabular}{lcc}
\hline \multicolumn{1}{c}{ Animal cohorts } & $\begin{array}{c}\text { Baseline } \mathrm{R}_{\mathrm{L}}{ }^{*} \\
\left(\mathrm{~cm} \mathrm{H}_{2} \mathrm{O} / \mathrm{mL} / \mathrm{s}\right)\end{array}$ & $\begin{array}{c}\text { Baseline Cdyn* } \\
\left(\mathrm{mL} / \mathrm{cm} \mathrm{H}_{2} \mathrm{O}\right)\end{array}$ \\
\hline Normoxic controls & $0.76 \pm 0.15$ & $0.020 \pm 0.004$ \\
Normoxic ventilated & $0.82 \pm 0.17$ & $0.022 \pm 0.003$ \\
Hyperoxic controls & $0.61 \pm 0.04$ & $0.026 \pm 0.004$ \\
Hyperoxic ventilated & $0.60 \pm 0.07$ & $0.024 \pm 0.005$ \\
Intubated only & $0.74 \pm 0.09$ & $0.028 \pm 0.007$ \\
Nonintubated controls & $0.81 \pm 0.1$ & $0.024 \pm 0.008$ \\
\hline
\end{tabular}

$*$ Mean \pm SD. 

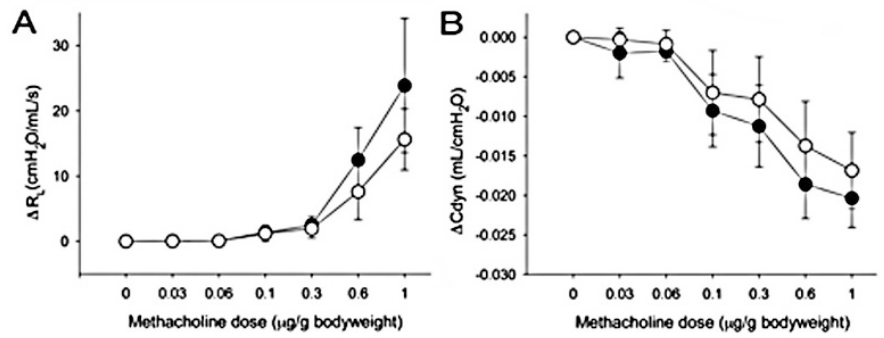

Figure 1. (A) Effect of increasing doses of intravenous methacholine on changes in lung resistance $\left(\mathrm{R}_{\mathrm{L}}\right)$ in normoxia ventilated $(\boldsymbol{\bullet}, n=7)$ and unventilated normoxic control animals $(\mathrm{O}, n=13)$. Responses of $\mathrm{R}_{\mathrm{L}}$ in the ventilated animals were of significantly greater magnitude $(p<0.01)$. Each data point represents mean \pm SD. $(B)$ Effect of increasing doses of intravenous methacholine on changes in lung compliance (Cdyn) in normoxia ventilated $(\bullet, n=7)$ and unventilated normoxic control animals $(\bigcirc, n=13)$. Responses of Cdyn in the ventilated animals were significantly greater $(p<$ $0.01)$. Each data point represents mean $\pm \mathrm{SD}$.
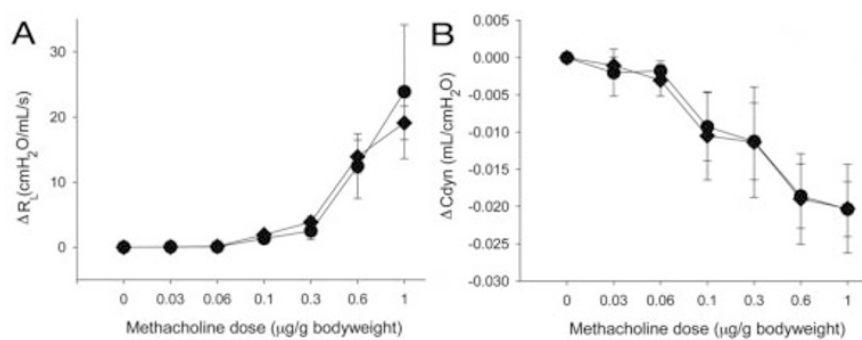

Figure 2. (A) Effect of increasing doses of intravenous methacholine on changes in lung resistance $\left(\mathrm{R}_{\mathrm{L}}\right)$ in normoxia ventilated $(\boldsymbol{\bullet}, n=7)$ and hyperoxia ventilated animals $(\bullet, n=8)$. Responses of $\mathrm{R}_{\mathrm{L}}$ were not different in the two groups $(p=0.98)$. Each data point represents mean $\pm \mathrm{SD}$. $(B)$ Effect of increasing doses of intravenous methacholine on changes in lung compliance (Cdyn) in normoxia ventilated $(\boldsymbol{\bullet}, n=7)$ and hyperoxia ventilated animals $(\forall, n=8)$. Responses of Cdyn were not different in the two groups $(p=0.74)$. Each data point represents mean \pm SD.

hyperoxia alone $(p<0.01)$, whereas changes in Cdyn were not significantly different $(p=0.27)$.

Effect of endotracheal intubation alone on airway reactivity. To delineate the effect of endotracheal intubation without mechanical ventilation, we compared an additional eight animals that underwent tracheal intubation with littermates who received no intervention $(n=8)$. There was no difference between groups in the response of $\mathrm{R}_{\mathrm{L}}(p=0.2$, Fig. $4 A)$ or Cdyn ( $p=0.38$, Fig. $4 B$ ) to intravenous methacholine.

Lung histology. No histologic inflammatory changes were seen by light microscopy in normoxic ventilated versus control rat lungs. Specifically, the number of inflammatory cells/ 100 epithelial cells in the peripheral airways $(100-400 \mu \mathrm{m})$ was not significantly different in normoxic ventilated versus control animal $(3.0 \pm 1.41$ versus $3.6 \pm 1.14, p=0.48)$. Smooth muscle was seen in most airways $>200 \mu \mathrm{m}$ as a oneto two-cell-thick layer, insufficient for definitive morphologic quantification.

There was no acute or chronic inflammation, no congestion, and no evidence of epithelial injury or ulceration seen in the distal trachea.

Myosin content. Western blot analysis for smooth muscle myosin heavy chain revealed a single band with a molecular mass of $204 \mathrm{kD}$ in lungs from room air ventilated and control
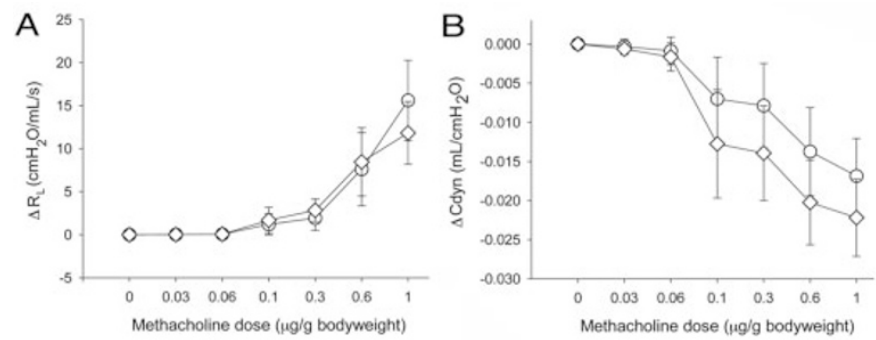

Figure 3. (A) Effect of increasing doses of intravenous methacholine on changes in lung resistance $\left(\mathrm{R}_{\mathrm{L}}\right)$ in unventilated normoxic controls $(\bigcirc, n=13)$ and hyperoxia exposed animals $(\diamond, n=13)$. Responses of $\mathrm{R}_{\mathrm{L}}$ were not different in the two groups $(p=0.82)$. Each data point represents mean $\pm \mathrm{SD}$. $(B)$ Effect of increasing doses of intravenous methacholine on changes in lung compliance (Cdyn) in unventilated normoxic controls $(\mathrm{O}, n=13)$ and hyperoxia exposed animals $(\diamond, n=13)$. Responses of Cdyn were significantly greater in the hyperoxia-exposed animals $(p<0.01)$. Each data point represents mean $\pm \mathrm{SD}$.
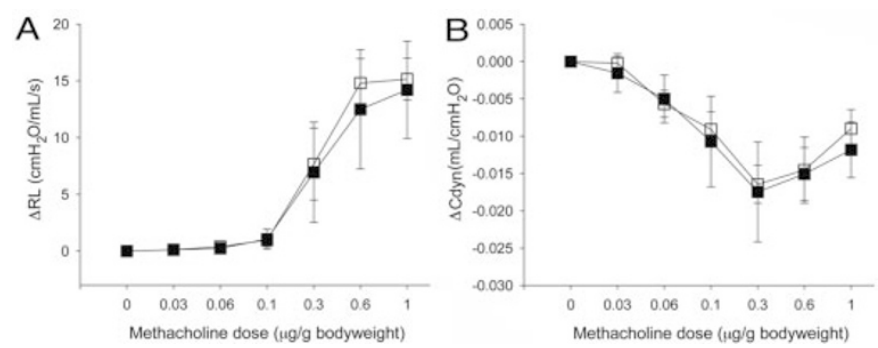

Figure 4. (A) Effect of increasing dosis of intravenous methacholine on changes in lung resistance $\left(\mathrm{R}_{\mathrm{L}}\right)$ in intubated, nonventilated animals $(\boldsymbol{\square}, n=$ 8) and controls $(\square, n=8)$. Responses of $\mathrm{R}_{\mathrm{L}}$ were not different in the two groups $(p=0.2)$. Each data point represents mean \pm SD. $(B)$ Effect of increasing doses of intravenous methacholine on changes in lung compliance (Cdyn) in intubated, nonventilated animals $(\mathbf{\square}, n=8)$ and controls $(\square, n=$ 8). Responses of Cdyn were not different in the two groups $(p=0.37)$. Each data point represents mean \pm SD.

animals (Fig. 5A). The content of myosin in lung tissue, including intrapulmonary airways, analyzed by densitometric scanning relative to the GAPDH, was comparable between control and normoxic ventilated samples when expressed in densitometric units per $40 \mu \mathrm{g}$ protein $(p=0.77$; Fig. $5 B)$.

\section{DISCUSSION}

The results of the present study show, for the first time, that a brief period of mechanical ventilation in rat pups increases bronchopulmonary constrictor responses to cholinergic stimulation $48 \mathrm{~h}$ after such exposure in the presence as well as absence of hyperoxic exposure. The study represents a potentially important model to investigate the mechanisms involved in airway hyperreactivity induced by neonatal lung injury, and the data support the concept that exposure to mechanical ventilation during a critical period of lung development contributes to pulmonary morbidity in the premature infant (11). Preterm infants with BPD exhibit increased airway contractile responsiveness both acutely and as a long-term sequela of their disease $(2,12)$. Although compromised airway function is most pronounced in children with a history of BPD (1), increased bronchial responsiveness is also common in prematurely born school-age children in the absence of BPD. At the same time, there has been a growing concern about the 
A
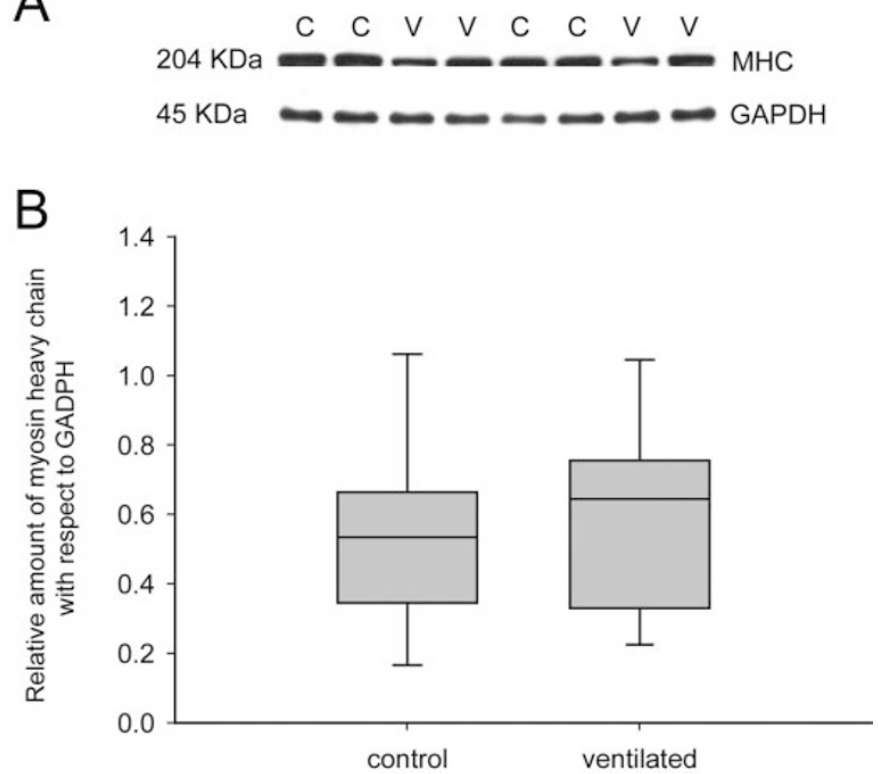

Figure 5. (A) Western blot analysis for smooth muscle myosin heavy chain in lungs from ventilated $(V)$ and control $(C)$ rat pups. $(B)$ Myosin content by Western blot in lungs from rat pups ventilated under normoxic conditions $v s$ normoxic controls. Data are displayed as median, 5th, 25th, 75th, and 95th percentiles.

potentially detrimental effects of neonatal mechanical ventilation. Rates of BPD seem to be lower in centers with judicious use of ventilators $(13,14)$, but it has been difficult to differentiate between variability in other aspects of neonatal care and the effect of mechanical ventilation on neonatal and postneonatal morbidity. There is therefore a compelling need to develop animal models that can specifically characterize the pathophysiologic consequences of even a brief period of neonatal mechanical ventilation.

Ongoing studies are evaluating ventilator-induced lung injury in early life. van Heeckeren et al. (10) demonstrated lower measurable lung volumes to inflation and an increased number of neutrophils in alveolar washes of preterm lambs after ventilation with a moderate amount of oxygen for a 2-h period compared with no ventilation or CPAP for $2 \mathrm{~h}$. Ventilation for 30 min after birth with high compared with low tidal volumes leads to persistently decreased lung compliance in preterm lambs (15). In preterm lambs, a 3-4 wk period of mechanical ventilation has been shown to disrupt lung development and produce histopathologic changes including greater smooth muscle thickness around terminal bronchioles similar to lungs of preterm infants dying of BPD (16). After several weeks of mechanical ventilation in the preterm baboon, decreased alveolarization is observed (17). In these studies of long-term ventilation, smooth muscle hypertrophy appeared to be a prominent feature of the pathophysiologic changes observed. This contrasts with the data from our relatively briefly ventilated rat pups in which we did not find histologic or biochemical evidence for increased smooth muscle mass despite increased airway reactivity.

Exposure to hyperoxia has been demonstrated to induce airway hyperreactivity in immature animals. Hershenson et al.
(18) found that exposure of 21-d- old rats to hyperoxia ( $>95 \%$ $\mathrm{O}_{2}$ for $8 \mathrm{~d}$ ) significantly increased in vivo airway cholinergic responsiveness. This was associated with increased airway epithelial and smooth muscle layer thickness in a separate cohort of animals. Denis et al. (7) described increased in vitro tracheal smooth muscle contraction to acetylcholine after a 14-d exposure of rat pups to $60 \%$ oxygen starting at the time of birth. In our current study, neither hyperoxic exposure alone nor addition of hyperoxia to mechanical ventilation affected the response of lung resistance to intravenous methacholine. This is not surprising given the relatively brief exposure time and consistent with findings by Szarek et al. (19), who found increased tracheal responses to electrical field stimulation under in vitro conditions in adult rats after 3-7 d but not after $1 \mathrm{~d}$ of hyperoxia. Airway hyperreactivity in response to hyperoxic exposure is therefore determined by duration and timing of exposure as well as concentration of oxygen used.

Two strengths of the rat pup model used in this study are the ability to ventilate the animals in $21 \%$ oxygen and to return them to their mother for future testing. Whereas we studied the effects of mechanical ventilation after a 2-d recovery period with their mother, this could be prolonged or shortened in future work. The age of $8 \mathrm{~d}$ for the exposure to mechanical ventilation was chosen for feasibility of tracheal intubation and avoidance of tracheotomy. The duration of ventilation in the initial experiments (normoxic ventilated versus control) ranged from 1.7 to $4 \mathrm{~h}$ due to variable duration of sedation effect. Subsequent increase in sedation assured a more standardized ventilatory duration of $4 \mathrm{~h}$ in the hyperoxic ventilated group. Nonetheless, there was no difference in airway responses to intravenous methacholine between animals ventilated in room air for 1.7-4 $\mathrm{h}$ and animals ventilated in hyperoxia for $4 \mathrm{~h}$. Therefore, the greater response of lung resistance to methacholine in ventilated rat pups might be present even after a shorter period of ventilation. The mode of ventilation used in this study did elicit a respiratory alkalosis, which may have aggravated the injurious effects of mechanical ventilation, and can be addressed in future studies employing this model.

In the present study, an observed increase in $\mathrm{R}_{\mathrm{L}}$ response to methacholine in ventilated animals was associated with a parallel decrease in Cdyn. These data suggest that relatively short-term mechanical ventilation affects reactivity not only of central airways but also of most peripheral airways and lung parenchyma. In addition, brief hyperoxic exposure may affect the compliance but not resistance response to cholinergic stimulation. This is consistent with our earlier work in piglets where we have shown that bronchoconstrictive substances given intravenously cause a decrease in Cdyn by contraction of periductal smooth muscle and/or lung parenchyma (20). Future studies may allow us to partition central versus peripheral contractile responses to bronchoconstriction and compare differential responses to inhaled versus systemically administered cholinergic agonists (21).

The duration of the exposure to mechanical ventilation was significantly shorter than that used by other investigators who found increased tracheal muscle mass after prolonged mechanical ventilation in $30 \%$ oxygen (8). Lack of histologic or 
biochemical evidence for a change in muscle mass in our ventilated animals is consistent with the failure of our intervention to cause a systematic effect of ventilation on baseline resistance or compliance, although a subtle effect might have been documented with a more sensitive technique and/or larger sample size. Lack of an increase in myosin content after brief mechanical ventilation suggests a functional rather than structural change in airway and tissue contractile properties. We were not able to obtain a quantitative measure of smooth muscle thickness due to insufficient amount of smooth muscle in the smaller airways, however, we did not find any gross histologic changes in the smooth muscle layer or evidence of inflammation in the airways and tissue parenchyma.

We can only speculate about the mechanisms involved in airway hyperresponsiveness induced by short-term mechanical ventilation. Impaired relaxant as well as increased constrictive mechanisms could be involved.

We have shown under in vivo conditions that nitric oxide (NO)-mediated relaxant responses are lost after hyperoxic exposure of rat pups (5). MacRitchie et al. (22) have found reduced endothelial nitric oxide synthase (eNOS) in airway epithelium after chronic ventilation with oxygen in the immature lamb, associated with an increased airway resistance. Comparable findings of neuronal nitric oxide synthase (eNOS) and eNOS deficiency have been observed in the immature baboon model of chronic lung disease (23). It is therefore conceivable that mechanical ventilation could impair NO and/or prostaglandin E2 signaling mechanisms that induce bronchodilatation. It is also possible that inflammatory mediators could have contributed to the observed increased airway reactivity in our model $(4,24,25)$. Although we made no attempt to measure cytokine responses to our intervention, we did not observe histologic evidence of an inflammatory cell influx in our analysis of lung specimens.

In summary, we have developed a model of immature lung injury and shown for the first time that brief ventilation alone without supplemental oxygen induced significantly increased airway reactivity measured by changes in $\mathrm{R}_{\mathrm{L}}$. This was paralleled by changes in Cdyn, suggesting that normoxic mechanical ventilation may elicit a contractile response in larger intrapulmonary airways as well as peripheral bronchopulmonary units. Physiologic changes expressed by increase in responsiveness to cholinergic agonists were not accompanied by morphologic or inflammatory changes in the airways and/or lung parenchyma, implicating a functional rather than anatomical basis for our findings. We speculate that mechanical ventilation without significant hyperoxic exposure may be a contributor to subsequent reactive bronchopulmonary disorders in premature infants even without a history of BPD.

\section{REFERENCES}

1. Pelkonen AS, Hakulinen AL, Turpeinen M 1997 Bronchial lability and responsiveness in school children born very preterm. Am J Respir Crit Care Med 156:11781184

2. Kilbride HW, Gelatt MC, Sabath RJ 2003 Pulmonary function and exercise capacity for ELBW survivors in preadolescence: effect of neonatal chronic lung disease. J Pediatr 143:488-493

3. Jobe AH, Bancalari E 2001 Bronchopulmonary dysplasia. Am J Respir Crit Care Med 163:1723-1729

4. Iben SC, Dreshaj IA, Farver CF, Haxhiu MA, Martin RJ 2000 Role of endogenous nitric oxide in hyperoxia- induced airway hyperreactivity in maturing rats. J Appl Physiol 89:1205-1212

5. Agani FH, Kuo NT, Chang CH, Dreshaj IA, Farver CF, Krause JE, Ernsberger P, Haxhiu MA, Martin RJ 1997 Effect of hyperoxia on substance P expression and airway reactivity in the developing lung. Am J Physiol 273:L40-L45

6. Belik J, Jankov RP, Pan J, Tanswell AK 2003 Chronic O2 exposure enhances vascular and airway smooth muscle contraction in the newborn but not adult rat. J Appl Physiol 94:2303-2312

7. Denis D, Fayon MJ, Berger P, Molimard M, De Lara MT, Roux E, Marthan R 2001 Prolonged moderate hyperoxia induces hyperresponsiveness and airway inflammation in newborn rats. Pediatr Res 50:515-519

8. Fukunaga T, Davies P, Zhang L, Hashida Y, Motoyama EK 1998 Prolonged high intermittent positive-pressure ventilation induces airway remodeling and reactivity in young rats. Am J Physiol 275:L567-L573

9. Burri PH 1974 The postnatal growth of the rat lung. III. Morphology. Anat Rec 180:77-98

10. van Heeckeren AM, Tscheikuna J, Walenga RW, Konstan MW, Davis PB, Erokwu B, Haxhiu MA, Ferkol TW 2000 Effect of pseudomas infection on weight loss, lung mechanics, and cytokines in mice. Am J Respir Crit Care Med 161:271-279

11. Jobe AH, Ikegami M 1998 Mechanisms initiating lung injury in the preterm. Early Hum Dev 53:81-94

12. Shaffer TH, Wolfson MR, Panitch HB 2004 Airway structure, function and development in health and disease. Pediatr Anaesth 14:3-14

13. Aly H, Milner JD, Patel K, El-Mohnades AA 2004 Does the experience with the use of nasal continuous positive airway pressure improve over time in extremely low birth weight infants? Pediatrics 114:697-702

14. Van Marter LJ, Allred EN, Pagano M, Sanocka U, Parad R, Moore M, Susser M, Paneth N, Leviton A, 2000 A Do clinical markers of barotraumas and oxygen toxicity explain interhospital variation in rates of chronic lung disease? Pediatrics 105:1194-1201

15. Wada K, Jobe AH, Ikegami M 1997 Tidal volume effects on surfactant treatment responses with the initiation of ventilation in preterm lambs. J Appl Physiol 83:1054-1061

16. Albertine KH, Jones GP, Starcher BC, Bohnsack JF, Davis PL, Cho S, Carlton DP, Bland R 1999 Chronic lung injury in preterm lambs. Am J Respir Crit Care Med 159:945-958

17. Coalson JJ, Winter VT, Siler-Khodr T, Yoder BA 1999 Neonatal Chronic Lung Disease in Extremely Immature Baboons. Am J Respir Crit Care Med;160:13331346

18. Hershenson MB, Aghili S, Punjabi N, Hernandez C, Ray DW, Garland A, Glagov S, Solway J 1992 Hyperoxia- induced airway hyperresponsiveness and remodeling in imnmature rats. Am J Physiol 262:L263-L269

19. Szarek JL, Ramsay HL, Andringa A, Miller ML 1995 Time course of airway hyperresponsiveness and remodeling induced by hyperoxia in rats. Am J Physiol 269:L227-L233

20. Dreshaj IA, Haxhiu MA, Potter CF, Agani FH, Martin RJ 1996 Maturational changes in responses of tissue and airway resistance to histamine. J Appl Physiol 81:1785-1791

21. Petak F, Hantos Z, Adamicza A, Asztalos T, Sly PD 1997 Methacholine-induced bronchoconstriction in rats: effects of intravenous vs. aerosol delivery. J Appl Physiol 82:1479-1487

22. MacRitchie AN, Albertine KH, Sun J, Lei PS, Jensen SC, Freestone AA, Clair PM, Dahl MJ, Godfrey EA, Carlton DP, Bland RD 2001 Reduced endothelial nitric oxide synthase in lungs of chronically ventilated preterm lambs. Am J Physiol Lung Cell Mol Physiol 281:L1011-L1020

23. Afshar S, Gibson LL, Yuhanna IS, Sherman TS, Kerecman JD, Grubb PH, Yoder BA, McCurnin DC, Shaul PW 2003 Pulmonary NO synthase expression is attenuated in a fetal baboon model of chronic lung disease. Am J Physiol Lung Cell Mol Physiol 284:L749-L758

24. Tremblay L, Valenza F, Ribeiro SP, Li J, Slutsky A, 1997 Injurious ventilatory strategies increase cytokines and c-fos m-RNA expression in an isolated rat lung model. J Clin Invest 99:944-952

25. Copland IB, Martinez F, Kavanagh BP, Engelberts D, McKerlie C, Belik J, Post M 2004 High Tidal Volume Ventilation Causes Different Inflammatory Responses in Newborn versus Adult Lung. Am J Respir Crit Care 169:739-748 